\title{
Archéopages
}

Archéopages

Archéologie et société

40 | 04-07/2014

Villages

\section{Genèse et structuration d'un habitat dédié à la forge}

\section{Martine Derbois}

\section{(2) OpenEdition}

\section{Journals}

Édition électronique

URL : https://journals.openedition.org/archeopages/610

DOI : 10.4000/archeopages. 610

ISSN : 2269-9872

\section{Éditeur}

INRAP - Institut national de recherches archéologiques préventives

\section{Édition imprimée}

Date de publication : 1 juin 2015

Pagination : 65

ISSN : 1622-8545

\section{Référence électronique}

Martine Derbois, « Genèse et structuration d'un habitat dédié à la forge », Archéopages [En ligne], 40 | 04-07/2014, mis en ligne le 01 juillet 2016, consulté le 24 janvier 2022. URL : http://

journals.openedition.org/archeopages/610; DOI : https://doi.org/10.4000/archeopages.610 
1. Le terrain est limité au nord par l'actuelle rue de Boissy qui reprend le tracé d'un ancien chemin antique. Cet axe permettait de circuler du gué de Précy-sur-0ise (ultérieurement remplacé par un pont) aux carrières d'extraction de pierre calcaire dites de SaintLeu-d'Esserent, localisées sur le hameau de Boissy. II longeait la villa galloromaine du « Pré Meunier » installée sur une carrière d'argiles, en limite de Précy et de Villers. Boissy ceinture le site à l'est tandis que trois contraintes naturelles le circonscrivent à l'oulest, à l'est et au sud : deux sources, ou résurgences des eaux de ruissellements, coulent vers le vallon où un ru intermittent et un marais les relient. Ces trois éléments seront aménagés et canalisés à la période moderne pour créer et alimenter le plan d'eau du château de Villers.

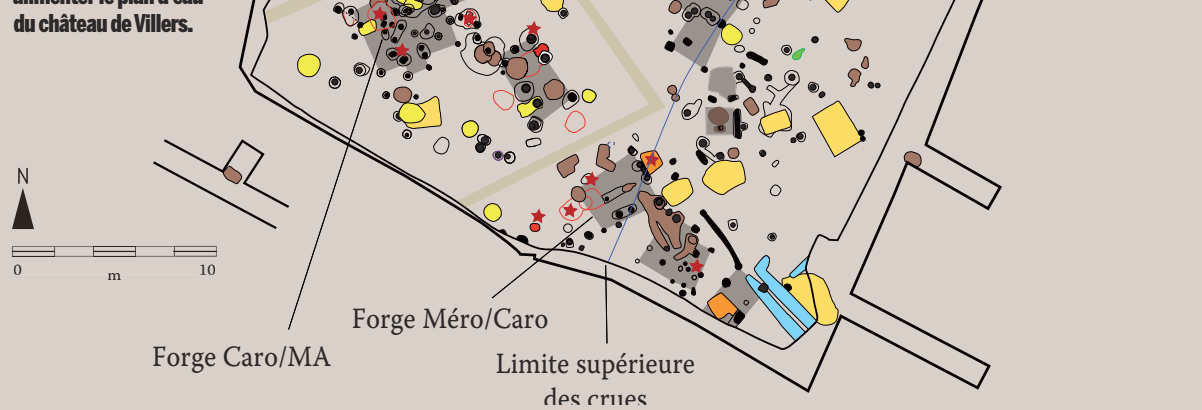

\section{Genèse et}

\section{structuration}

\section{d'un habitat}

\section{dédié à la forge}

Martine Derbois, Inrap

Villers-sous-Saint-Leu est implanté sur la frange sud du département de l'Oise et la rive droite de la rivière homonyme. Le site s'inscrit sur le versant doux, exposé au sud-est, d'un vallon humide qui draine les eaux de ruissellements du plateau boisé vers la vallée. Le hameau ou domaine s'installe sur un lieu vierge de toute occupation anthropique. Il sera pérenne du vire siècle à la fin des $\mathrm{xII}^{\mathrm{e}}$-xIII ${ }^{\mathrm{e}}$ siècles en raison de son contexte particulièrement favorable au développement et à la diffusion de son artisanat métallurgique. Le combustible est disponible à proximité immédiate, le minerai est aisément transporté par voie d'eau ou réseau routier. Les débouchés commerciaux sont importants avec le développement des domaines abbatiaux le long de l'Oise, des activités dans les carrières proches, les ports et l'essor agricole. Une intense activité de forge, basée essentiellement sur le travail du fer, avec cependant des traces plus bronze et du plomb, y est réalisée durant toute son existence malgré plusieurs incendies et des crues destructrices [ill. 1]. Ces dernières ont influé sur la conservation des vestiges et il n'en subsiste plus qu'une superficie d'environ $6000 \mathrm{~m}^{2}$. Fn outre, le territoire du hameau semble répondre à des contraintes territoriales fortes qui obligent à des reconstructions sur les lieux mêmes, rendant la datation des vestiges fort complexe en raison du peu de mobilier recueilli dans chaque structure, de sa qualité possiblement résiduelle ou intrusive et de la chronologie fort large des productions. À la période mérovingienne, l'établissement est fondé à la base d'un versant de vallon sec où l'eau est aisément accessible par le biais d'un puits peu profond. Ce Villariculum (le petit domaine), installation à vocation artisanale et agro pastorale satellite, est mentionné en 797 (Lebègue, 1994). fugaces concernant celui du cuivre, $d u$
Cave, cellier

Fond de cabane, annexe

Bâtiment

- Trou de poteau, sablière

Puits

Four, foyer

Aire de chauffe, cendrier

Traces de métallurgie

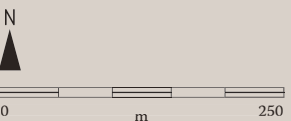

Fosse

Chablis

Chemin, place

Structure arasée

Il est relié par un chemin secondaire au réseau viaire de Boissy. L'habitat mérovingien comprend de nombreux fonds de cabane et petites annexes, des fours domestiques ou à usage métallurgique, des silos et de l'habitat sur poteaux difficilement distinguable sous les reconstructions postérieures. Tous sont installés dans des espaces spécifiques.

À la suite d'un incendie d'origine inconnue et de la remontée des eaux, la structure du village évolue entre le vIII et le $\mathrm{Ix}^{\mathrm{e}}$ siècle vers un parcellaire en "étoile ". L'habitat se densifie. Des sections de clôtures en bois (le reste en haies ?) délimitent des secteurs autour d'une place où a été creusé un nouveau puits communautaire (P2). Des voies de circulation sont alors perceptibles entre et dans les parcelles. Le bâti sur poteaux se développe et inclut des caves, des celliers et des salles carrées, légèrement encavées, comme sur le site contemporain proche du " Martray " à Précy-sur-Oise. Les incendies se succèdent sans que l'on puisse en déterminer les causes : activité métallurgique, raids vikings, rivalités seigneuriales locales ou du roi de France avec ses voisins normands. Le site est reconstruit une dernière fois avec un nouveau puits (P3), mais son déclin s'amorce jusqu'à son abandon jusqu'à la fin du $\mathrm{xIr}^{\mathrm{e}}$ siècle ou au $\mathrm{xIr}^{\mathrm{e}}$ siècle après un nouvel incident et, peut-être, le creusement avorté d'un nouveau puits. Le site se replie ou rejoint le cœur du nouveau village, le Villari de 1124 et le Villare subtus sanctum Lupum de 1250. Le nouvel emplacement, moins sensible aux variations de débit du ruisseau, est installé le long d'une voie perpendiculaire à la rue de Boissy qui mène à l'Oise et sur laquelle se fixe définitivement le village. Ce transfert semble concomitant de la construction d'une église en pierre par le seigneur des lieux, le sieur Poyen ou Payen. I'état de la documentation ne permet pas d'établir aujourd'hui si l'activité de forge s'est déplacée avec la population. 